\title{
Passing through the renal clearance barrier: toward ultrasmall sizes with stable ligands for potential clinical applications
}

This article was published in the following Dove Press journal:

International Journal of Nanomedicine

25 April 2014

Number of times this article has been viewed

\author{
Xiao-Dong Zhang' \\ Jiang Yang ${ }^{2}$ \\ Sha-Sha Song' \\ Wei Long' \\ Jie Chen' \\ Xiu Shen' \\ Hao Wang' \\ Yuan-Ming Sun' \\ Pei-Xun Liu' \\ Saijun Fan'
}

'Tianjin Key Laboratory of Molecular Nuclear Medicine, Institute of Radiation Medicine, Chinese Academy of Medical Sciences and Peking Union Medical College, Tianjin, People's Republic of China; ${ }^{2}$ Department of Biological Systems Engineering, University of Wisconsin-Madison, Madison, WI, USA
Correspondence: Xiao-Dong Zhang N 238, Nankai district, Tianjin, 300192, People's Republic of China Tel +862285683046

Fax +862285683046

Email xiaodongzhang@irm-cams.ac.cn

\begin{abstract}
The use of nanoparticles holds promise for medical applications, such as X-ray imaging, photothermal therapy and radiotherapy. However, the in vivo toxicity of inorganic nanoparticles raises some concern regarding undesirable side effects which prevent their further medical application. Ultrasmall sub-5.5 $\mathrm{nm}$ particles can pass through the barrier for renal clearance, minimizing their toxicity. In this letter we address some recent interesting work regarding in vivo toxicity and renal clearance, and discuss the possible strategy of utilizing ultrasmall nanomaterials. We propose that small hydrodynamic sized nanoclusters can achieve both nontoxic and therapeutic clinical features.
\end{abstract}

Keywords: in vivo clearance, gold nanoparticles, small size

\section{Dear editor}

Biomedical applications of inorganic nanoparticles have been investigated for several years. ${ }^{1-3}$ It was conceived that nanoparticles hold potential for use as X-ray contrast agents, fluorescence imaging agents, photothermal therapy agents, and radiosensitizers. ${ }^{4-12}$ However, their toxicity, especially in vivo toxicity, is still a huge challenge for further applications in medicine. ${ }^{13-17}$ In earlier years, several groups have demonstrated that citric acid-coated nanoparticles are not toxic in vitro, and they demonstrated that human cells were viable and highly active even at millimolar levels. ${ }^{18,19}$ However, the in vitro toxicity cannot necessarily reflect the in vivo toxicity. The in vivo toxicity of nanoparticles mainly arises from accumulation of nanoparticles in the liver and spleen. Specifically, nanoparticles with sizes ranging from 10 to $250 \mathrm{~nm}$ show very high distributions in the liver and spleen due to reticuloendothelial system (RES) absorption. ${ }^{20}$ Several groups have reported that large nanoparticles accumulate in the liver and spleen, and they are not cleared easily. ${ }^{21-23}$ Large nanoparticles can be absorbed rapidly by macrophages, because the small naked gold nanoparticles will first react with blood proteins and then form larger nanoparticle-protein complexes, namely protein corona. ${ }^{24-28}$ The high distribution in the liver and spleen can induce potential liver toxicities. ${ }^{7,27,29}$

In order to decrease toxicity, one of the most effective options is to decrease the size of the nanoparticles, making them behave as supermolecules which can induce "leakage" of nanoparticles in vivo mediated by the kidney. ${ }^{30,31}$ Choi et al proposed that nanoparticles can be cleared when the hydrodynamic size of nanoparticles is decreased to $5.5 \mathrm{~nm} .{ }^{32}$ We can define this hydrodynamic size as the size of the renal clearance barrier (Figure 1). Indeed, it has been shown that small quantum dots can present with 


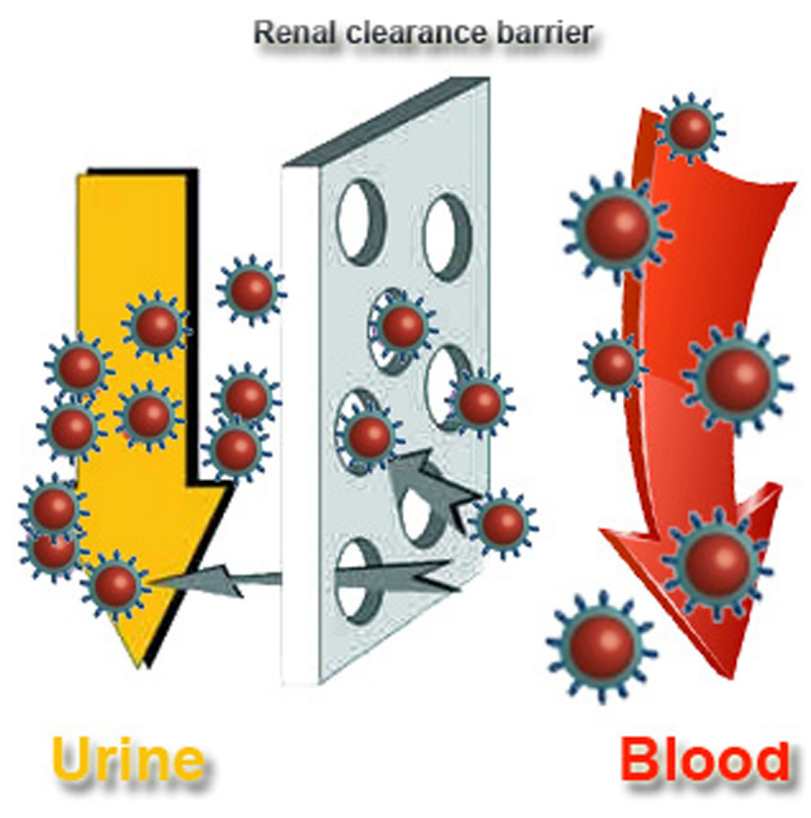

Figure I Outline of the renal clearance barrier.

highly efficient renal clearance. ${ }^{33}$ However, only being small in size is not enough, because naked nanoparticles can still react with blood proteins and form larger complexes. For example, Hainfeld et al used X-ray imaging of $1.9 \mathrm{~nm}$ gold nanoparticles, ${ }^{6}$ and when ultrahigh doses $(2.7 \mathrm{~g} \mathrm{Au} / \mathrm{kg})$ of gold nanoparticles are used in mice, many were found in the blood vessels. Indeed, these nanoparticles are difficult to clear. Furthermore, toxic effects were not demonstrated, but the high dose was considered to be very dangerous.

Polyethylene glycol (PEG) is widely used in coating of nanoparticles for nanomedical applications. ${ }^{34,35}$ However, PEG-coated sub-5 nm nanoparticles cannot be cleared by the kidney, ${ }^{27,36,37}$ even when the hydrodynamic size of PEG-coated gold nanoparticles decreased to $3 \mathrm{~nm} .{ }^{36}$ Ultrasmall $\mathrm{BaGdF}_{5}$-based upconversion nanoparticles also cannot be cleared by the kidney. ${ }^{38}$ Thus, it is clear that only having a small size is not sufficient for the clearance of nanoparticles.

To overcomes these obstacles, ultrasmall nanoclusters or particles with stable ligands have been proposed. Specifically, nanoparticles with small endogenous ligands would be highly desirable. For example, sub-5 nm gold nanoparticles with glutathione (GSH) ligands, a kind of endogenous small molecule, are highly efficient in renal clearance. ${ }^{36}$ Meanwhile, the sub-2 nm GSH-protected Au nanoclusters are also highly efficient in renal clearance and they also show low toxicity after injection..$^{39}$ Even after 30 days, the GSH-protected gold nanoclusters did not show any significant toxicity. Using $1.2 \mathrm{~nm}$ gold nanoparticles as cores, the GSH-protected gold nanoparticles can be cleared by the kidney even at the dose of $60 \mu \mathrm{M} .{ }^{40}$ In contrast, bovine serum albumin (BSA)-protected Au nanoclusters in a hydrodynamic size of $6 \mathrm{~nm}$ cannot pass the renal clearance barrier and show minor liver toxicities. In another independent work, the renal clearance of dithiolated polyaminocarboxylate-coated gold nanoparticles was reported ${ }^{41}$ In this work, the hydrodynamic size was as large as $6.6 \mathrm{~nm}$, higher than the proposed value of $5.5 \mathrm{~nm}$ for the renal clearance barrier, but the nanoparticles can still induce a highly efficient renal clearance. ${ }^{41}$ Therefore, this illustrates that stable ligands are as important as the hydrodynamic size in renal clearance of nanoparticles.

With the exception of gold-based nanomaterials as mentioned above, other ultrasmall nanomaterials such as carbon nanomaterials and semiconducting quantum dots have also been widely investigated. For example, Huang et al have shown that amine-functionalized carbon dots in a $4.1 \mathrm{~nm}$ hydrodynamic size can be cleared renally. ${ }^{42}$ However, carboxylated graphene quantum dots in 3-6 nm hydrodynamic sizes cannot go through the renal clearance barrier and thus cause an appreciable distribution in the liver and spleen. It is not yet clear why these graphene quantum dots cannot pass through the renal clearance barrier, but one possible reason could be their instability exogenously. As such, it is still necessary to obtain renallyclearable graphene quantum dots with stable ligands for further medical applications. A similar phenomenon was observed using ultrasmall semiconducting nanoparticles. Polyvinylpyrrolidone-protected $\mathrm{Gd}_{2} \mathrm{O}_{3}$ nanoparticles in a $2.9 \mathrm{~nm}$ ultrasmall size can achieve efficient renal clearance. ${ }^{43}$ However, $1.5 \mathrm{~nm} \mathrm{\textrm {Ag } _ { 2 }}$ Se nanoparticles cannot be metabolized by the kidney. ${ }^{44}$

Besides this, it is interesting to control the clearance of nanoparticles mediated by macrophages. For example, Chou et al used DNA to control the biological delivery and clearance of inorganic nanoparticles by organizing them into colloidal superstructures. ${ }^{45}$ The nanoparticles behave as building blocks whose size, surface chemistry and assembly architecture dictate the overall superstructure design. These superstructures are able to interact with cells and tissues as a function of their designs, but subsequently degrade into building blocks that can escape biological sequestrations. Thereby, this design realizes successful clearance of nanoparticles resulting in intact biofunctions.

Despite some significant advances with small nanoparticles, some difficulties still exist. When the core size of the nanoparticles is decreased to sub- $3 \mathrm{~nm}$, the physical and chemical properties of some materials might 
be lost or altered. For gold-based nanomaterials, the surface plasmon resonance of gold disappears when diameters are decreased to sub-5 nm. ${ }^{46}$ Instead, unique electronic structures and optical properties are introduced. ${ }^{47,48}$ In this situation, the photothermal efficiency of nanoparticles will be considerably affected due to sharply decreased absorption. As for quantum dots, the quantum dots will be easily quenched or bleached with their sizes decreased to sub-5 nm. ${ }^{49}$ Meanwhile, as the quantum size effect is induced by small sizes, the band gap of quantum dots will be widened and the wavelength for photoluminescence will shift to the region of shorter wavelengths. ${ }^{50}$ Taking carbon nanomaterials into account with their size deceased to sub-5 nm, the band gap of graphene nanosheets or graphene quantum dots increases to $2-3 \mathrm{eV}$ according to band gap engineering, while the fluorescence of carbon nanotubes will disappear. ${ }^{51-54}$ As the diameter is decreased to sub-5 nm levels, magnetic properties of some magnetic materials such as $\mathrm{Fe}_{3} \mathrm{O}_{4}$ will be influenced. Meanwhile, it would be more difficult to dope them with other elements. Lots of upconversion materials will lose their fluorescence characteristics with their size decreased to $5 \mathrm{~nm}$. At the size of sub-5 nm, strong surface activities can jeopardize applications, with surface modifications as a typical example. Another challenge lies in how to monitor concentrations of ultrasmall organic nanoparticles, because it is still unclear whether nanoparticles will be broken down in vivo, and in what quantity. To be specific, when nanoparticles are injected into mice, lots of particles will interact with proteins and may then be broken down in vivo. In this case, it will be very difficult to determine how many nanoparticles still stay in the body, making the related clearance complicated. In summary, obtaining ultrasmall particles with good physical and chemical properties for medical applications is still an unmet need and remains a challenge for further research.

\section{Acknowledgments}

This work was supported by the National Natural Science Foundation of China (Grant No 81000668), Natural Science Foundation of Tianjin (Grant No 13JCQNJC13500), the Subject Development Foundation of Institute of Radiation Medicine, CAMS (Grant No SF1207, SZ1336), and PUMC Youth Fund and the Fundamental Research Funds for the Central Universities (Grant No 3332013043).

\section{Disclosure}

The authors report no conflicts of interest in this work.

\section{References}

1. Leutwyler WK, Bürgi SL, Burg1 H. Semiconductor clusters, nanocrystals, and quantum dots. Science. 1996;271(5251):933-937.

2. Chan WC, Nie S. Quantum dot bioconjugates for ultrasensitive nonisotopic detection. Science. 1998;281(5385):2016-2018.

3. Bruchez M, Moronne M, Gin P, Weiss S, Alivisatos AP. Semiconductor nanocrystals as fluorescent biological labels. Science. 1998;281(5385):2013-2016.

4. Kim D, Park S, Lee JH, Jeong YY, Jon S. Antibiofouling polymercoated gold nanoparticles as a contrast agent for in vivo X-ray computed tomography imaging. J Am Chem Soc. 2007;129(24):7661-7665.

5. Huang X, El-Sayed IH, Qian W, El-Sayed MA. Cancer cell imaging and photothermal therapy in the near-infrared region by using gold nanorods. J Am Chem Soc. 2006;128(6):2115-2120.

6. Hainfeld JF, Slatkin DN, Smilowitz HM. The use of gold nanoparticles to enhance radiotherapy in mice. Phys Med Biol. 2004;49(18):N309-N315.

7. Zhang XD, Wu D, Shen X, et al. Size-dependent radiosensitization of PEG-coated gold nanoparticles for cancer radiation therapy. Biomaterials. 2012;33(27):6408-6419.

8. Zhang XD, Chen J, Luo Z, et al. Enhanced tumor accumulation of sub-2 nm gold nanoclusters for cancer radiation therapy. Adv Healthc Mater. 2014;3(1):133-141.

9. Zhang XD, Chen J, Min Y, et al. Metabolizable Bi2Se3 Nanoplates: Biodistribution, Toxicity, and Uses for Cancer Radiation Therapy and Imaging. Advanced Functional Materials. 2014;24(12):1718-1729.

10. Liu Z, Cai W, He L, et al. In vivo biodistribution and highly efficient tumour targeting of carbon nanotubes in mice. Nat Nanotechnol. 2007;2(1):47-52.

11. Hong G, Lee JC, Robinson JT, et al. Multifunctional in vivo vascular imaging using near-infrared II fluorescence. Nat Med. 2012;18(12): $1841-1846$.

12. Wu D, Zhang X-D, Liu P-X, Zhang L-A, Fan F-Y, Guo M-L. Gold nanostructure: fabrication, surface modification, targeting imaging, and enhanced radiotherapy. Current Nanoscience. 2011;7(1):110-118.

13. Murphy CJ, Gole AM, Stone JW, et al. Gold nanoparticles in biology: beyond toxicity to cellular imaging. Acc Chem Res. 2008;41(12): 1721-1730.

14. Boisselier E, Astruc D. Gold nanoparticles in nanomedicine: preparations, imaging, diagnostics, therapies and toxicity. Chem Soc Rev. 2009;38(6):1759-1782

15. Chen J, Wang H, Long W, et al. Sex differences in the toxicity of polyethylene glycol-coated gold nanoparticles in mice. Int J Nanomedicine. 2013;8:2409-2419.

16. Hudoklin S, Zupančič D, Makovec D, Kreft ME, Romih R. Gold nanoparticles as physiological markers of urine internalization into urothelial cells in vivo. Int J Nanomedicine. 2013;8:3945-3953.

17. Zhang XD, Wu HY, Wu D, et al. Toxicologic effects of gold nanoparticles in vivo by different administration routes. Int $J$ Nanomedicine. 2009;5:771-781.

18. Lewinski N, Colvin V, Drezek R. Cytotoxicity of nanoparticles. Small. 2008;4(1):26-49.

19. Pan Y, Neuss S, Leifert A, et al. Size-dependent cytotoxicity of gold nanoparticles. Small. 2007;3(11):1941-1949.

20. De Jong WH, Hagens WI, Krystek P, Burger MC, Sips AJ, Geertsma RE. Particle size-dependent organ distribution of gold nanoparticles after intravenous administration. Biomaterials. 2008;29(12):1912-1919.

21. Zhang G, Yang Z, Lu W, et al. Influence of anchoring ligands and particle size on the colloidal stability and in vivo biodistribution of polyethylene glycol-coated gold nanoparticles in tumor-xenografted mice. Biomaterials. 2009;30(10):1928-1936.

22. Lipka J, Semmler-Behnke M, Sperling RA, et al. Biodistribution of PEG-modified gold nanoparticles following intratracheal instillation and intravenous injection. Biomaterials. 2010;31(25):6574-6581.

23. Balasubramanian SK, Jittiwat J, Manikandan J, Ong CN, Yu LE, Ong WY. Biodistribution of gold nanoparticles and gene expression changes in the liver and spleen after intravenous administration in rats. Biomaterials. 2010;31(8):2034-2042. 
24. Monopoli MP, Walczyk D, Campbell A, et al. Physical-chemical aspects of protein corona: relevance to in vitro and in vivo biological impacts of nanoparticles. J Am Chem Soc. 2011;133(8):2525-2534.

25. Cedervall T, Lynch I, Lindman S, et al. Understanding the nanoparticle-protein corona using methods to quantify exchange rates and affinities of proteins for nanoparticles. Proc Natl Acad Sci U S A. 2007;104(7):2050-2055.

26. Lundqvist M, Stigler J, Elia G, Lynch I, Cedervall T, Dawson KA. Nanoparticle size and surface properties determine the protein corona with possible implications for biological impacts. Proc Natl Acad Sci US A. 2008;105(38):14265-14270.

27. Zhang XD, Wu D, Shen X, et al. Size-dependent in vivo toxicity of PEGcoated gold nanoparticles. Int J Nanomedicine. 2011;6:2071-2081.

28. Schlachter EK, Widmer HR, Bregy A, et al. Metabolic pathway and distribution of superparamagnetic iron oxide nanoparticles: in vivo study. Int J Nanomedicine. 2011;6:1793-1800.

29. Ma P, Luo Q, Chen J, et al. Intraperitoneal injection of magnetic Fe3O4nanoparticle induces hepatic and renal tissue injury via oxidative stress in mice. Int J Nanomedicine. 2012;7:4809-4818.

30. Gorth DJ, Rand DM, Webster TJ, Silver nanoparticle toxicity in Drosophila: size does matter. Int J Nanomedicine. 2011;6:343-350.

31. Puvanakrishnan P, Park J, Chatterjee D, Krishnan S, Tunnell JW. In vivo tumor targeting of gold nanoparticles: effect of particle type and dosing strategy. Int J Nanomedicine. 2012;7:1251-1258.

32. Choi HS, Liu W, Misra P, et al. Renal clearance of quantum dots. Nat Biotechnol. 2007;25(10):1165-1170.

33. Fischer HC, Liu L, Pang KS, Chan WC. Pharmacokinetics of nanoscale quantum dots: in vivo distribution, sequestration, and clearance in the rat. Advanced Functional Materials. 2006;16(10):1299-1305.

34. Xie J, Xu C, Kohler N, Hou Y, Sun S. Controlled PEGylation of Monodisperse Fe3O4 Nanoparticles for Reduced Non-Specific Uptake by Macrophage Cells. Advanced Materials. 2007;19(20):3163-3166.

35. Niidome T, Yamagata M, Okamoto Y, et al. PEG-modified gold nanorods with a stealth character for in vivo applications. $J$ Control Release. 2006;114(3):343-347.

36. Zhou C, Long M, Qin Y, Sun X, Zheng J. Luminescent gold nanoparticles with efficient renal clearance. Angewandte Chemie International Edition. 2011;123(14):3226-3230.

37. Choi CHJ, Zuckerman JE, Webster P, Davis ME, Targeting kidney mesangium by nanoparticles of defined size. Proc Natl Acad Sci USA. 2011;108(16):6656-6661.

38. Yang D, Dai Y, Liu J, et al. Ultra-small $\mathrm{BaGdF}_{5}$-based upconversion nanoparticles as drug carriers and multimodal imaging probes. Biomaterials. 2014;35(6):2011-2023

39. Zhang XD, Wu D, Shen X, Liu PX, Fan FY, Fan SJ. In vivo renal clearance, biodistribution, toxicity of gold nanoclusters. Biomaterials. 2012;33(18):4628-4638.
40. Simpson CA, Salleng KJ, Cliffel DE, Feldheim DL. In vivo toxicity, biodistribution, and clearance of glutathione-coated gold nanoparticles. Nanomedicine. 2013;9(2):257-263.

41. Alric C, Miladi I, Kryza D, et al. The biodistribution of gold nanoparticles designed for renal clearance. Nanoscale. 2013;5(13): 5930-5939.

42. Huang X, Zhang F, Zhu L, et al. Effect of Injection Routes on the Biodistribution, Clearance, and Tumor Uptake of Carbon Dots. ACS Nano. 2013;7(7):5684-5693.

43. Fang J, Chandrasekharan P, Liu XL, et al. Manipulating the surface coating of ultra-small $\mathrm{Gd}_{2} \mathrm{O}_{3}$ nanoparticles for improved $\mathrm{T}_{1}$-weighted MR imaging. Biomaterials. 2014;35(5):1636-1642.

44. Gu YP, Cui R, Zhang ZL, Xie ZX, Pang DW. Ultrasmall near-infrared $\mathrm{Ag} 2 \mathrm{Se}$ quantum dots with tunable fluorescence for in vivo imaging. J Am Chem Soc. 2011;134(1):79-82.

45. Chou LY, Zagorovsky K, Chan WC. DNA assembly of nanoparticle superstructures for controlled biological delivery and elimination. Nature Nanotechnology. 2014;9(1):148-155.

46. Qian H, Zhu Y, Jin R. Atomically precise gold nanocrystal molecules with surface plasmon resonance. Proc Natl Acad Sci USA. 2012;109(3): 696-700.

47. Luo Z, Yuan X, Yu Y, et al. From aggregation-induced emission of $\mathrm{Au}$ (I)-thiolate complexes to ultrabright Au (0)@ Au (I)-thiolate core-shell nanoclusters. J Am Chem Soc. 2012;134(40): $16662-16670$

48. Xie J, Zheng Y, Ying JY. Protein-directed synthesis of highly fluorescent gold nanoclusters. J Am Chem Soc. 2009;131(3):888-889.

49. Dong C, Qian H, Fang N, Ren J. Study of fluorescence quenching and dialysis process of CdTe quantum dots, using ensemble techniques and fluorescence correlation spectroscopy. J Phys Chem B. 2006;110(23): 11069-11075

50. Klimov V, Mikhailovsky A, Xu S, et al. Optical gain and stimulated emission in nanocrystal quantum dots. Science. 2000;290(5490): 314-317.

51. Cognet L, Tsyboulski DA, Rocha J-DR, Doyle CD, Tour JM, Weisman RB. Stepwise quenching of exciton fluorescence in carbon nanotubes by single-molecule reactions. Science. 2007;316(5830):1465-1468.

52. Pan D, Zhang J, Li Z, Wu M. Hydrothermal Route for Cutting Graphene Sheets into Blue-Luminescent Graphene Quantum Dots. Advanced Materials. 2010;22(6):734-738.

53. Han MY, Özyilmaz B, Zhang Y, Kim P. Energy band-gap engineering of graphene nanoribbons. Phys Rev Lett. 2007;98(20):206805.

54. Wang X, Ouyang Y, Li X, Wang H, Guo J, Dai H. Room-temperature allsemiconducting sub-10-nm graphene nanoribbon field-effect transistors. Phys Rev Lett. 2008;100(20):206803.
International Journal of Nanomedicine

\section{Publish your work in this journal}

The International Journal of Nanomedicine is an international, peerreviewed journal focusing on the application of nanotechnology in diagnostics, therapeutics, and drug delivery systems throughout the biomedical field. This journal is indexed on PubMed Central, MedLine, CAS, SciSearch ${ }^{\circledR}$, Current Contents ${ }^{\circledR} /$ Clinical Medicine,
Dovepress

Journal Citation Reports/Science Edition, EMBase, Scopus and the Elsevier Bibliographic databases. The manuscript management system is completely online and includes a very quick and fair peer-review system, which is all easy to use. Visit http://www.dovepress.com/ testimonials.php to read real quotes from published authors. 